\title{
Políticas públicas para o desenvolvimento regional sustentável e preservação ambiental no contexto amazônico: Um enfoque na RDS do Tupé no Amazonas
}

\author{
Public policies for sustainable regional development and environmental preservation in the \\ Amazon context: A focus on the Tupé RDS in Amazonas \\ Políticas públicas para el desarrollo regional sostenible y la preservación ambiental en el contexto \\ amazónico: Un enfoque en el Tupé RDS en Amazonas
}

\section{Resumo}

Este artigo é parte integrante de uma pesquisa de mestrado do Programa de Pós-graduação em Educação da Universidade Federal do Amazonas (PPGE/UFAM), financiada pela Coordenação de Aperfeiçoamento de Pessoal em Nível Superior - CAPES e Fundação de Amparo à Pesquisa do Estado do Amazonas - FAPEAM. O objetivo do mesmo consiste em analisar as Políticas públicas para o desenvolvimento regional sustentável e preservação ambiental no contexto amazônico, a partir do enfoque na Reserva de Desenvolvimento Sustentável do Tupé no Estado do Amazonas. Delineada pela abordagem qualitativa e apoiada do método dialético que possibilitou a compreensão dos fenômenos e suas contradições, a mesma ainda contou com auxilio da pesquisa bibliográfica e documental. Constatou-se que o Plano de Gestão da RDS do Tupé apresenta contradições em relação à realidade amazônica. O estudo aponta para a necessidade do Plano de Gestão da RDS do Tupé dialogar com as Políticas públicas para o desenvolvimento regional sustentável e preservação ambiental no contexto amazônico, que possibilite aos moradores da reserva trabalhar, viver, estudar e ter direito a uma vida digna no seu local de origem.

Palavras-chave: Políticas públicas; Desenvolvimento regional sustentável; RSD do Tupé.

\begin{abstract}
This article is an integral part of a master's research by the Postgraduate Program in Education at the Federal University of Amazonas (PPGE/UFAM), financed by the Coordination for the Improvement of Higher Education Personnel - CAPES and the State of State Research Support Foundation Amazonas - FAPEAM. Its objective is to analyze Public Policies for sustainable regional development and environmental preservation in the Amazon context, from the standpoint of the Tupé Sustainable Development Reserve in the State of Amazonas. Outlined by the qualitative approach and supported by the dialectical method that made it possible to understand the phenomena and their contradictions, it also had the aid of bibliographical and documentary research. It was found that the Management Plan of the Tupé RDS presents contradictions in relation to the Amazonian reality. The study points to the need for the Tupé RDS Management Plan to dialogue with public policies for sustainable regional development and environmental preservation in the Amazon context, enabling the reserve's residents to work, live, study and have the right to a dignified life in your place of origin.
\end{abstract}

Keywords: Public policy; Sustainable regional development; Tupé's RSD. 


\begin{abstract}
Resumen
Este artículo es parte integral de una investigación de maestría del Programa de Posgrado en Educación de la Universidad Federal del Amazonas (PPGE / UFAM), financiado por la Coordinación para el Perfeccionamiento del Personal de Educación Superior - CAPES y la Fundación de Apoyo a la Investigación del Estado. de Amazonas FAPEAM. Su objetivo es analizar las Políticas Públicas para el desarrollo regional sustentable y la preservación ambiental en el contexto amazónico, desde el punto de vista de la Reserva de Desarrollo Sustentable Tupé en el Estado de Amazonas. Delineado por el enfoque cualitativo y apoyado por el método dialéctico que permitió comprender los fenómenos y sus contradicciones, contó también con la ayuda de la investigación bibliográfica y documental. Se encontró que el Plan de Manejo del Tupé RDS presenta contradicciones en relación a la realidad amazónica. El estudio apunta a la necesidad del Plan de Manejo de Tupé RDS para dialogar con las políticas públicas para el desarrollo regional sustentable y la preservación ambiental en el contexto amazónico, permitiendo a los pobladores de la reserva trabajar, vivir, estudiar y tener derecho a una vida digna en su lugar de origen.
\end{abstract}

Palabras clave: Políticas públicas; Desarrollo regional sostenible; RSD de Tupé.

\title{
1. Introdução
}

Assim, o presente artigo é parte integrante de uma pesquisa de mestrado concluída e vinculada ao Programa de Pósgraduação em Educação da Universidade Federal do Amazonas (PPGE/UFAM), financiada pela Coordenação de Aperfeiçoamento de Pessoal em Nível Superior - CAPES e Fundação de Amparo à Pesquisa do Estado do Amazonas FAPEAM.

O mesmo tem como objetivo analisar as Políticas públicas para o desenvolvimento regional sustentável e preservação ambiental no contexto amazônico, a partir do enfoque na Reserva de Desenvolvimento Sustentável do Tupé no Estado do Amazonas. Delineada pela abordagem qualitativa e apoiada do método dialético que possibilitou a compreensão dos fenômenos e suas contradições, a mesma ainda contou com auxilio da pesquisa bibliográfica e documental.

O estudo encontra-se organizado em 6 partes: a principio descrevemos a metodologia utilizada na pesquisa, posteriormente tratamos sobre Política de preservação ambiental em reservas de desenvolvimento sustentável no Brasil; o Desenvolvimento Sustentável e desenvolvimento regional sustentável na Amazônia; a Reservas de Desenvolvimento Sustentáveis (RDS) como política ambiental no contexto amazônico e o Surgimento da RDS Tupé, uma vez que se tornou, a partir de nosso entendimento, uma das ações implementadas na região amazônica, no estado do Amazonas, a partir da conferência internacional sobre conscientização pública para a sustentabilidade, ocorrida na Grécia em 1997; fazendo parte de uma das iniciativas do Brasil para a Década da Educação para o Desenvolvimento Sustentável, no período de 2005 a 2014. Discutimos ainda a proposta de Desenvolvimento Sustentável presente no Plano de Gestão da RDS do Tupé; assim como as Metas e estratégias do Plano de Gestão da RDS do Tupé.

Por fim, tecemos as considerações finais sobre o estudo, apresentando reflexões sobre os principais achados da pesquisa e suas contradições em relação à realidade amazônica, compreendendo e enfatizando a importância de se pensar as Políticas públicas para o desenvolvimento regional sustentável e preservação ambiental no contexto amazônico na RDS do Tupé no Amazonas, assumindo a necessidade de elaboração e implementação de metas, propostas e políticas que atendam essas populações em todas as suas necessidades, tal como infraestrutura, educação, saúde, lazer e etc.

\section{Metodologia}

Este artigo é parte integrante de uma pesquisa de mestrado do Programa de Pós-graduação em Educação da Universidade Federal do Amazonas (PPGE/UFAM), financiada pela Coordenação de Aperfeiçoamento de Pessoal em Nível Superior - CAPES e Fundação de Amparo à Pesquisa do Estado do Amazonas - FAPEAM. Trata-se de um estudo de natureza qualitativa e apoiada do método dialético que possibilitou a compreensão dos fenômenos e suas contradições. A mesma ainda contou com auxilio da pesquisa bibliográfica e documental. 
As pesquisas de natureza qualitativa são aquelas nos quais é importante a interpretação por parte do pesquisador com suas opiniões sobre o fenômeno em estudo (Pereira et al., 2018), possibilitando que se retirasse da realidade dados que pudessem ser analisados (contrastar e validar). De acordo com Gonzaga (2007, p. 73) a abordagem qualitativa possui uma série de características que a diferem de uma abordagem quantitativa, como destaca-se a seguir:

a) A teoria constitui uma reflexão em e a partir da prática, visto que a realidade é percebida e constituída não só por fatos observáveis e externos, mas também por significados, símbolos e interpretações elaboradas pelo próprio sujeito através de uma interação com os demais; b) Tenta compreender a realidade, tomando como princípio o fato de que o conhecimento das investigações de caráter hermenêutico e interativo é individual e pessoal, fazendo com que os valores passem a fazer parte da investigação e façam parte da realidade, e a mesma investigação seja influenciada pelos valores do contexto social e cultural; c) Descreve o fato no qual se desenvolve o acontecimento, a partir de uma natureza de investigação que produz dados descritivos: as próprias palavras das pessoas, faladas ou escritas, e a conduta observável; d) A profunda nos diferentes motivos dos fatos, pois a vida social, além de ser considerada como algo que flui continuamente, também é aberta, fazendo com que a realidade social e cultural não venha a ser conhecida somente através de reações observáveis e medíveis do homem, dado que ignora o campo da intencionalidade e o significado das ações e que o individuo é um sujeito interativo, comunicativo, que compartilha significados, pois a relação entre sujeito e objeto é de interação, especialmente quando o objeto de estudo é a pessoa humana. (Gonzaga, 2007).

A abordagem qualitativa assume uma realidade dinâmica, fundamentada na realidade e orientada ás descobertas, de caráter exploratório, expansionista, descritivo e indutivo. Interessa-se em compreender a conduta humana a partir do próprio marco de quem atua. A pesquisa qualitativa é indutiva, pois os pesquisadores iniciam seus estudos com questionamentos pouco formulados o que faz com que haja uma reflexão acerca da situação que o pesquisador se encontrava em relação ao tema proposto naquele momento inicial. (Gonzaga, 2007)

Gonzaga (2007) relata algumas características do pesquisador que desenvolve uma pesquisa qualitativa. Ele diz que o pesquisador defende uma compreensão geral dos fenômenos, ou seja, ele estuda as pessoas no contexto de seu passado e das situações que se encontram no presente, além de trazer consigo a preocupação com os efeitos que podem causar nas pessoas que são os seus objetos de estudo, ou seja, há interação entre o pesquisador e os sujeitos da pesquisa de uma forma natural, fazendo com que o próprio pesquisador venha se colocar no lugar do sujeito, identificando características comuns a serem compartilhadas.

Já a pesquisa bibliográfica segundo Gil (2002), é desenvolvida com base em material já elaborado, constituído principalmente de livros e artigos científicos. Esse tipo de pesquisa permite ao pesquisador uma amplitude de conhecimentos e dados sobre o objeto pesquisado maior do que se ele fosse realizar pessoalmente a pesquisa. Porém, o investigador deve ter cuidado com a veracidade das fontes bibliográficas.

Posteriormente, foi realizada a Pesquisa Documental que é muito parecida com a pesquisa bibliográfica, com um diferencial nas fontes, enquanto a pesquisa bibliográfica desenvolve-se a partir de materiais analisados por diversos autores, a pesquisa documental tem como fontes materiais que ainda não tiveram uma leitura analítica por parte de algum investigador. A pesquisa documental é um método de compreensão e produção do conhecimento científico acerca de determinados recortes da realidade sócio-educacional. (Silva et al., 2009, p. 4554).

Para os autores et al (2009, p. 4556), a pesquisa documental "enquanto método de investigação da realidade social, não traz uma única concepção filosófica de pesquisa ”, ou seja, ela pode ser utilizada em várias abordagens de pesquisa, tanto aquelas de natureza positivista como as de natureza mais crítica. Na pesquisa documental, não somente os documentos escolhidos respondem as questões da pesquisa, mas também a análise deles, fazendo com que o pesquisador necessite adquirir uma postura mais crítica na compreensão do problema e nas relações que estabelece entre ele e o contexto em que está inserido, na construção das conclusões e como comunica os resultados da pesquisa. 
Por isso, para Silva et al. (2009, p. 4557), a pesquisa documental "permite a investigação de determinada problemática não em sua interação imediata, mas de forma indireta, por meio do estudo dos documentos que são produzidos pelo homem e por isso revelam o seu modo de ser, viver e compreender um fato social".

De acordo com Gil (2002, p. 51) "há os documentos de "primeira mão" que não receberam nenhum tratamento analítico. Nesta categoria, estão os documentos conservados em arquivos públicos e privados [...]" e outros documentos como cartas 1pessoais, diários, fotografias e etc. A pesquisa analisou os seguintes documentos sobre o objeto de estudo proposto: Os documentos de Criação da Reserva de Desenvolvimento Sustentável e o Plano de Gestão da RDS do Tupé (2008-20016).

Por isso, a pesquisa documental permitiu realizar a investigação da problemática em curso, não de forma direta, mas de forma indireta, por meio do estudo dos documentos que são produzidos pelo homem e por isso revelam o seu modo de ser, viver e compreender um fato social. (Silva et al., 2009, p. 4557).

\section{Política de Preservação Ambiental em Reservas de Desenvolvimento Sustentável no Brasil}

A política ambiental engloba uma série de atuações governamentais que determina ou tenta produzir resultados sobre a qualidade ambiental ou o uso dos recursos naturais (Kraft, 1996 apud Brizolla, Allebrandt \& Zanatta, 2020, p.8). No que concernem as áreas de preservação ambiental é aquela que se caracteriza pela conservação da diversidade social, entre as quais destacamos as diversas culturas com requisitos técnicos e produtivos; e biológica caracterizada pelas várias espécies da flora e fauna que precisam dar continuidade a sua espécie a fim de não serem extintos e em favor da continuidade da preservação dos ambientes naturais de seus territórios.

A partir disso, surge uma nova nomenclatura denominada Área de Proteção Ambiental (APA), caracterizada por uma extensa área natural destinada à proteção e conservação dos atributos bióticos, ou seja, a fauna e flora; estéticos ou culturais existentes naquela área que são utilizados pelas populações locais, contribuindo para uma melhor qualidade de vida e com o objetivo de proteger os ecossistemas regionais. O objetivo principal de uma APA é a conservação de processos naturais e da biodiversidade, através da orientação e da adequação de várias atividades humanas.

Nessas áreas de proteção ambiental é permitida a ocupação humana, pois é possível conciliar a ocupação humana da área com o uso sustentável dos recursos naturais que ali se fazem presentes. Essas áreas de proteção ambiental podem estar localizadas em propriedades públicas ou particulares (União, Estados e Municípios) sem que ocorra a desapropriação das terras particulares. Porém, as atividades e usos desenvolvidos nestas localidades devem obedecer a regras específicas. As áreas que pertencem aos poderes públicos organizarão as condições para as visitas públicas e pesquisas científicas pelo órgão responsável da unidade e da mesma forma se a área de proteção ambiental estiver em domínio particular, os donos da propriedade deverão criar condições para que haja pesquisa e visitação do público d e acordo com as restrições locais.

Originalmente criadas pela Lei 6902/1981, as áreas de proteção ambiental são hoje reguladas pela Lei 9.985/00 do Sistema Nacional de Unidades de Conservação da Natureza (SNUC). De acordo com o cadastro Nacional de Unidades de conservação (CNUC) que mapeia todas as áreas de proteção ambiental no país, até o ano de 2015, existiam 294 áreas de proteção ambiental no Brasil; 32 na esfera federal, 185 na esfera estadual e 77 na municipal.

Destacamos a importância das cadeias produtivas em Agricultura e Extrativismo e Pecuária nos locais da "várzea do Solimões no estado do Amazonas que estabelecem padrões sociais e econômicos de uso e manejo dos solos onde a função social da propriedade e a necessidade de conservação ambiental estão em permanente disfunção" (Noda, 2007, p.28). Com a expansão das redes de funções de cadeias produtivas ocorre uma valorização no campo econômico dessas áreas, causando transformações nas estruturas nos setores de produção devido à abrangência das áreas de várzea.

De acordo com Noda (2007) outra questão relevante que vem promovendo a disfunção é o constante processo de concentração fundiária recorrente da produção em pecuária e o acesso ás áreas florestadas ou produtivas. Este é um dos 
problemas que ocorrem nas áreas de preservação ambiental devido à apropriação dos pecuaristas de forma ilícita das áreas que são florestadas, implicando um total desrespeito às leis de preservação dos ambientes naturais e de floresta no contexto amazônico. Filho (2006, p.139) aponta "a conservação da biodiversidade no longo prazo, que obrem um enraizamento social local maior para as áreas protegidas e que garantam justiça social na distribuição dos custos e benefícios [...]”. O autor fala da relação entre os grupos locais, como os caboclos, e a natureza, que podem criar parcerias de diversas maneiras a fim de viabilizar uma definição legal desses atores sociais que pertencem às áreas de preservação ambiental, promovendo não somente a conservação dessas áreas, mas a qualidade de vida para as suas populações.

\section{Desenvolvimento Sustentável e Desenvolvimento Regional Sustentável na Amazônia}

O desenvolvimento Sustentável baseia-se em teorias desenvolvimentistas, que podem ser neoliberais ou marxistas, e que tem como modelo as sociedades ocidentais para as demais sociedades do mundo. O termo "desenvolvimento" foi citado pela primeira vez em 1949, pelo presidente Harry Truman, dos Estados Unidos da América, quando foi tomar posse no Congresso referindo-se aos países pobres. Diante disso, os franceses, criaram outro termo, chamado de "terceiro mundo", para diferenciar os países ricos capitalistas, chamados de países de primeiro mundo dos países socialistas, designados de países de segundo mundo (Enríquez, 2010).

Já os estudos de Ferreira (2020, p.3) indicam que o termo Sustentabilidade,

[...] foi utilizado pela primeira vez pela Internacional Union for the Conservation of Nature and Natural Resources (IUCN), em Ottawa - Canadá no ano de 1986 onde foram apresentados os requisitos para se obter a sustentabilidade sendo eles a integração entre desenvolvimento e conservação da natureza, satisfação das necessidades humanas, busca da equidade e justiça social, autodeterminação social e respeito à diversidade cultural e a manutenção da integridade ecológica.

Há diversos autores cujos estudos retratam diferentes categorias sobre desenvolvimento, dentre eles podemos destacar: Foster-Carter (1976), para quem há dois paradigmas opostos no debate sobre desenvolvimento: desenvolvimento ocidental (mainstream) e neomarxista; Roxborough (1979) classifica as teorias do desenvolvimento em endógenas e exógenas; Hirschman (1982) identifica cinco principais escolas: 1) neomarxista, 2) neoclássica, 3) clássico-marxista, 4) paradigma do desenvolvimento ocidental e 5) teorias do desenvolvimento predominantes nos anos 1940 e 1950 (paradigma ortodoxo); Muller (1998) propõe cinco classificações: 1) desenvolvimento como crescimento; 2) industrialização como resposta ativa; 3) crítica ao crescimento; 4) dependência e desenvolvimento capitalista na periferia- o desenvolvimento nos anos 1960 na América Latina [...] (Enríquez, 2010, p. 16). 41

Dentre as teorias que explicam o desenvolvimento, destacamos as Propostas de Desenvolvimento Sustentável que tem como objetivo sustentar ou elevar, simultaneamente, o meio ecológico, incluindo a qualidade ambiental e o estoque de recursos, o bem-estar econômico e a justiça social (Enríquez, 2010, p. 98). Neste caso, se busca encontrar um equilíbrio entre as três formas de desenvolvimento sem que um afete de forma negativa o outro, pois não adianta uma nação alcançar progresso econômico se há prejuízos imensuráveis à questão ecológica e vice-versa. De acordo com o referido autor, o desenvolvimento sustentável é uma prioridade a ser analisada, discutida e colocada em prática pelas sociedades.

Enríquez (2010) revela que o tema do desenvolvimento tem assumido diferentes denominações na obra de Ignacy Sachs (2004), tais como desenvolvimento endógeno, ecodesenvolvimento, desenvolvimento sustentável [...]. Porém, há diferenciações entre essas terminologias a partir do modo como o desenvolvimento ocorre nas sociedades, de maneira saudável ou desenfreada, havendo equilíbrio ou não com a natureza. 
O desenvolvimento sustentável de Sachs é contra o desenvolvimento exercido pelas elites e é a favor de um modelo de desenvolvimento includente e sustentável, diferentemente de outros autores que afirmam que o desenvolvimento deve manter as relações de dominados e dominantes nas sociedades.

Ele ainda ressalta que os países subdesenvolvidos não devem se basear em modelos dos países ricos para alcançarem o desenvolvimento e que os modelos antigos de desenvolvimento devem apenas servir de estudo de superação para novas soluções; destaca ainda que o desenvolvimento deve acontecer se as desigualdades sociais forem erradicadas, não prevalecendo que uma minoria se estabeleça em detrimento de uma maioria excluída e marginalizada (Sachs, 1986; 2004 apud Enríquez, 2010).

O termo desenvolvimento sustentável, para as instituições internacionais como o Banco Mundial e a UNESCO, está relacionado ao crescimento econômico, justiça social e equilíbrio ecológico, porém na prática, funciona de maneira bem contraditória com a realidade. O modelo de industrialização tardia é capaz de modernizar alguns centros ou setores da economia, mas incapaz de oferecer um modelo de desenvolvimento equilibrado da sociedade inteira (Bruseke, 1995, p.37).

A Amazônia o desenvolvimento sustentável vem sendo discutido inclusive por programas de pós-graduação da Universidade Federal do Amazonas articulado a discussões de políticas públicas e desenvolvimento regional sustentável. Diante das dificuldades enfrentadas pelas populações frente ao desenvolvimento, verificamos na Amazônia uma situação não muito diferente de exclusão dessas populações, bem como desigualdade crescente entre elas e as elites dominantes em nosso país:

A globalização tem levado a uma exacerbação da pobreza nessas áreas rurais, principalmente naquelas de difícil acesso. Na Amazônia, são mínimos, quando não existentes, os serviços de educação, saúde, comunicação, transporte [...]. De fato, nas áreas interioranas dos altos rios e das terras firmes, pouco se recebe em termos dos benefícios que os impostos deveriam propiciar; e, como se sabe, os impostos não são baixos no Brasil. Inclusive, o jornal "O Globo" noticiou que no mundo quem mais pagou imposto nos últimos seis anos foi a classe média brasileira. Assim, os benefícios, que supostamente deveriam ser equivalentemente distribuídos, não chegam até essas populações (Simonian, 2005, p. 40).

Nesta proposta de desenvolvimento sustentável é preciso rejeitar o crescimento empobrecedor ou crescimento perverso que gera concentração de renda, exclusão social e uso predatório dos recursos naturais; o mal desenvolvimento (Enríquez, 2010). É necessário conhecer quais as condições que devem ser praticadas para que se estabeleça o bom desenvolvimento-endógeno, aquele que crie condições internas de desenvolvimento para um país e sua população, evitando as importações e valorizando as atividades internas de produção.

O planejamento moderno é uma solução para que haja o desenvolvimento sustentável, porém ele deve ser participativo e dialógico e requer a participação de vários sujeitos envolvidos no processo através de acordos com as autoridades públicas, empresas, organização de trabalhadores e sociedade civil organizada (Sachs, 2004 apud Enríquez, 2010).

\section{Reservas de Desenvolvimento Sustentáveis (RDS) como Política Ambiental no Contexto Amazônico e o Surgimento da RDS Tupé}

As Reservas de Desenvolvimento Sustentável (RDS)foram instituídas com alei n 9.985, de 18 de julho de 2000, regulamenta o art. 225, § $1^{\circ}$, incisos I, II, III e VII da Constituição Federal de 1988, que institui o Sistema Nacional de Unidades de Conservação da Natureza e de outras providências. No seu art. 20 define a Reserva de Desenvolvimento Sustentável como: 
Uma área natural que abriga populações tradicionais, cuja existência baseia-se em sistemas sustentáveis de exploração dos recursos naturais, desenvolvidos ao longo das gerações e adaptados ás condições ecológicas locais e que desempenham um papel fundamental na proteção da natureza e na manutenção da diversidade biológica (Brasil, 2000).

A Reserva de Desenvolvimento Sustentável tem como objetivo básico a preservação da natureza e, paralelo a isso, a garantia das condições e dos meios necessários para a melhoria dos modos e da qualidade de vida e exploração dos recursos naturais das populações locais que habitam nessas áreas de preservação. Também faz parte dos seus objetivos a valorização, conservação e aperfeiçoamento dos conhecimentos de técnicas de manejo do ambiente promovido pelas suas populações. A RDS é de domínio público e se houverem propriedades privadas estabelecidas em suas áreas devem ser, quando necessárias, desapropriadas de acordo com a lei em vigor.

A sua gestão se faz através de um conselho deliberativo presidido pelo órgão responsável por sua administração e é formado por representantes de órgãos públicos, de organizações da sociedade civil e das populações tradicionais moradores dessas áreas de acordo com o regulamento e no ato da criação da Unidade. Nesta lei são estabelecidas as condições das atividades que serão desenvolvidas na Reserva de Desenvolvimento Sustentável:

I- é permitida e incentivada a visitação pública, desde que compatível com os interesses locais e de acordo com o disposto no plano de manejo da área;

II- é permitida e incentivada à pesquisa científica voltada à conservação da natureza, a melhor relação das populações residentes com seu meio e a educação ambiental, sujeitando-se a prévia autorização do órgão responsável pela administração da unidade, às condições e restrições por estes estabelecidas e às normas previstas em regulamento;

III- deve ser sempre considerado o equilíbrio dinâmico entre o tamanho da população e a conservação;

IV- é admitida a exploração de componentes dos ecossistemas naturais em regime de manejo sustentável e a substituição da cobertura vegeta por espécies cultiváveis, desde que sujeitas ao zoneamento, ás limitações legais e ao Plano de Manejo da área (Brasil, 2000).

Diante do exposto, verificamos que independente das áreas estarem sob o domínio público ou privado, deverá ser oferecida, tanto pelo gestor do poder público ou dos proprietários de terras localizadas nas áreas protegidas, as condições necessárias de visitação pública de acordo com os interesses locais e amparo às pesquisas científicas voltadas à conservação da natureza; além do comprometimento dos grupos locais residentes de conservarem essas áreas de preservação, explorando os recursos naturais de forma sustentável, sem agredir o meio ambiente ou explorando de forma desordenada, além das suas necessidades locais e para fins de comercialização ou obtenção de lucros.

No capítulo IV desta mesma lei, de Título "Da criação, Implantação e Gestão das Unidades de Conservação", relata que as unidades de conservação são criadas por ato do Poder Público e que antes da sua criação devem ser realizados estudos técnicos e de consulta pública que permitam identificar a localização, a dimensão e os limites mais adequados para a unidade e em consonância com o regulamento. Neste caso, o poder público tem o dever fornecer informações adequadas ás populações locais ou a partes interessadas nesta construção.

No que concerne a criação da RDS de Tupé. A RDS de Tupé é situada na zona rural de Manaus, à margem esquerda do Rio Negro, numa distância de $25 \mathrm{~km}$ em linha reta da zona urbana e faz parte de uma das Unidades de Conservação do baixo Rio Negro. Ela também possui uma localização privilegiada no Estreito, área essencial para controle da região, por meio da proteção e fiscalização da navegação do Rio Negro. A RDS do Tupé é formada por uma extensa diversidade biológica que visa a interação dos seus recursos naturais com as populações residentes no local.

No seu processo de criação identificamos algumas das políticas públicas desenvolvidas na Unidade de Conservação e a ausência de tantas outras que viabilizariam uma melhor qualidade de vida aos grupos locais. Em 1990, o poder público municipal com o objetivo de proteger a área onde está localizado o lago do Tupé, declarou a Praia do Tupé como Área de Relevante Interesse Ecológico (ARIE) por meio da Lei Orgânica do Município de Manaus. No ano de 1995, foi criada a 
Unidade Ambiental do Tupé (UNA-Tupé) que passou a fazer parte do sistema Municipal de Unidades de Conservação. A gestão ambiental daquela localidade foi administrada pela Secretaria de Meio Ambiente (SEDEMA, atualmente SEMMAS) estabelecendo aquela área como Espaço Territorial de Relevante Interesse Ecológico (através do Decreto Municipal n 4.581 , de 18 de junho de 1999). A SEDEMA instituiu o Regulamento da Área de Relevante Interesse Ecológico do Tupé, denominado ARIE-Tupé, demarcando os limites espaciais e determinando as diretrizes e estratégias para a gestão da unidade.

No art. $2^{\circ}$, inciso XVII da Lei ${ }^{\circ}$ 9.985, de 18 de julho de 2000, que instituiu o Sistema Nacional de Unidades de Conservação (SNUC), diz que o Plano de Gestão é o documento Técnico que estabelece o zoneamento e as normas de uso de uma unidade de Conservação (UC). A legislação estadual do Amazonas através da lei complementar no 53 de 05 de junho de 2007, instituiu o Sistema Estadual de Unidades de Conservação (SEUC), onde ressalta que o Plano de Gestão além de estabelecer o zoneamento e as normas que devem regular o uso da área e o manejo dos recursos naturais, é responsável pela implantação da estrutura física que a gestão das unidades necessitará. No artigo 33, a SEUC informa que as Unidades de Conservação devem elaborar um Plano de Gestão num período de cinco anos a partir da data de sua criação. Por isso, a Secretaria Municipal do Meio Ambiente e Sustentabilidade (SEMMAS), elaborou no ano de 2008 em parceria com o Ministério do Meio Ambiente, o Plano de Gestão da RDS do Tupé.

Assim o Plano de Gestão da RDS do Tupé foi elaborado, de acordo com as determinações legais deve ser revisado a fim de que atenda as circunstâncias atuais da UC, aperfeiçoe os mecanismos e estratégias de gestão e atinja suas metas na gestão das unidades. Diante disso, a Prefeitura de Manaus através da SEMMAS, contratou uma consultoria jurídica a fim de realizar essa revisão no Plano de Gestão da UC.

Com a criação da Lei $\mathrm{n}^{\circ}$ 9985, de 18 de julho de 2000, as áreas protegidas que foram instituídas no período anterior teriam que ser reavaliadas, a fim de que se enquadrassem nas novas normas das Unidades de Conservação. Diante do exposto, a UMA-Tupé foi enquadrada para a categoria de Reserva de Desenvolvimento Sustentável, através do Decreto Municipal n 8044, de 25 de Agosto de 2005 que criou a Reserva de Desenvolvimento Sustentável do Tupé.

No Plano de Gestão (20084, p. 22) a RDS Tupé possui o objetivo básico de preservar a natureza e, ao mesmo tempo, assegurar as condições e os meios necessários para a reprodução, melhoria dos modos e qualidade de vida; além de promover meios necessários de exploração de recursos naturais dessas populações tradicionais com o desafio de valorizar, cultivar e aperfeiçoar as técnicas de manejo do ambiente promovidas pelas suas populações.

Plano de Gestão da RDS do Tupé foi elaborado em 2008. Em 2016 foram realizadas oficinas e atividades de campo para elaboração do volume I do plano de gestão - diagnósticos e em 2017 foi elaborado o volume II do plano de gestão planejamento.

Dentre as políticas fundiárias na UC podemos destacar que o artigo 18 do SNUC institui que para a regularização fundiária nessas unidades deverá haver a desapropriação de áreas particulares estabelecidas dentro dos seus limites e em sequência será emitido os contratos de Concessão de Direito Real de Uso (CDRU), sendo o instrumento legal indicado pela SNUC na garantia do direito de uso de terra pelas comunidades. Porém, não é tão simples assim, uma vez que existe uma enorme burocracia nos procedimentos administrativos e uma morosidade no andamento dos processos judiciais, a contar também pela escassez de recursos financeiros, orçamentários e humanos.

De acordo com a Secretaria de Estado de Política Fundiária (SPF), a área do Tupé é de domínio da União, por isso a gestão da Unidade de Conservação deve solicitar a transferência dessas terras para o domínio Municipal de Manaus através de negociação junto ao INCRA (Instituto Nacional de Colonização e Reforma Agrária). Dessa forma, serão concedidos os Contratos de Concessão de Direito Real de Uso para as comunidades tradicionais ali existentes, garantindo às populações dessas áreas um documento que comprove sua moradia e posse de terra e com isso possam adquirir financiamentos, benefícios do INSS (Instituto Nacional de Direito Social e Plano de Manejo dos recursos naturais). 
Com a criação da Zona Franca de Manaus em 1967, através do Decreto-Lei 288, de 28 de fevereiro, houve um incentivo econômico na região. Durante esse período até a atualidade houve um grande desafio em formular uma política de desenvolvimento autossustentável que possibilitasse a integração econômica da região Amazônica sem ônus aos bens naturais ali existentes. No entanto, verificamos que o projeto de integração tem dado passos modestos e que essas comunidades tradicionais da Amazônia vêm sofrendo com os impactos de exclusão, desvalorização e preconceito diante de suas realidades.

Na RDS do Tupé existem seis comunidades denominadas de Agrovila, Julião, Nossa Senhora do Livramento, Colônia Central, São João do Tupé e Tatulândia. Após um estudo da UFAM, juntamente com as Comunidades e a SEMMAS, foi realizada uma divisão de 18 distritos nas Comunidades do Tupé.

Muitas das famílias que viviam na RDS do Tupé desistiram de morar nessas áreas devido à infraestrutura e geração de renda, de acordo com um questionário aplicado nas Comunidades de Julião e Agrovila, durante o Mapeamento dos Recursos Naturais, em 2016, 18\% dos moradores apresentaram o desejo de sair das suas comunidades no prazo de cinco anos (Plano de Gestão da RDS do Tupé, 2016). Percebemos a ausência de políticas públicas básicas que deveriam ser promovidas pelos poderes públicos em prol da melhoria da qualidade de vida dessas populações. Há um grande fluxo de famílias que decidem sair de suas comunidades e partirem para a cidade de Manaus, porém ao se depararem com a falta de trabalho e de condições para sobreviverem nas cidades, retornam para as suas comunidades de origem.

Em algumas Comunidades da RDS do Tupé, identificamos a existência de uma infraestrutura básica como a presença de escolas, casinhas da saúde, energia elétrica, sedes da SEMMAS ou de Associações de Moradores, igrejas, centros comunitários, entre outros. Porém, cada comunidade possui uma realidade distinta da outra, enquanto uma possui escola, por exemplo, outras não possuem e seus moradores precisam se deslocar para as comunidades mais próximas ou partirem para a cidade de Manaus a fim de obterem o acesso à educação escolar. As políticas públicas chegam a essas comunidades em forma de conta-gotas, não gerindo condições básicas de sobrevivência a essas populações locais.

\section{A proposta de Desenvolvimento Sustentável Presente no Plano de Gestão da RDS do Tupé}

Inicialmente verificamos que o Plano de Gestão da RDS do Tupé está instituído na Lei n 9.985, de 18 de julho de 2000, que estabelece o Sistema Nacional de Unidades de Conservação (SNUC) e o reconhece como documento técnico, responsável pelo zoneamento e as normas de uso de uma Unidade de Conservação. O SNUC declara que as terras pertencentes às Unidades de Conservação que queiram regularizar-se deverão ser desapropriadas se forem de natureza particular e posteriormente deverá ser emitido o Contrato de Concessão de Direito Real de Uso-CDRU, que é o documento apontado no SNUC para garantir o direito de uso da terra pelas comunidades (Manaus, 2006 p. 26).

Identificamos no Plano de Gestão que a legislação complementar do Estado do Amazonas (Lei n ${ }^{\circ} 53$ de 05 de junho de 2007) estabelece o Sistema Estadual de Unidades de Conservação (SEUC) e dispõe que o Plano de Gestão é um documento técnico e gerencial e diz respeito ao zoneamento e as normas quanto ao uso da terra e o manejo dos recursos naturais, inclusive a implantação de estrutura física necessária à gestão da unidade. (Lei Complementar n ${ }^{\circ} 53$, art. $2^{\circ}$, inciso XI, 2007).

Também é citada a Lei Complementar $n^{\circ} 53$, de 5 de junho de 2007, que relata que após a data de criação, as Unidades de Conservação devem dispor de um Plano de Gestão num prazo de cinco anos. No caso da nossa região, a Secretaria de Meio Ambiente e Sustentabilidade (SEMMAS), por meio do Projeto Corredores Ecológico e em parceria com o Ministério do Meio Ambiente, criou o Plano de Gestão da RSD do Tupé. Essas disposições legais orientam que seja revisado o Plano de Gestão de REDES do Tupé por uma empresa de Consultoria Ambiental. A revisão do Plano de Gestão das REDES do Tupé aponta como um dos objetivos a serem executados: 
Aprimorar e fortalecer as estratégias de Gestão, atualizar as informações referentes aos recursos naturais e as Comunidades. Bem como identificar de que forma se dá o uso dos recursos e os meios para preservá-los, tendo em vista os objetivos de criação da UC (Manaus, 2016, p. 13).

De acordo com a Secretaria de Estado de Política Fundiária (SPF), toda a área do Tupé pertence à União e todas as terras devem ser repassadas para a Prefeitura Municipal de Manaus por solicitação da gestão da UC, o que deve ser realizado juntamente com o INCRA (Instituto Nacional de Colonização e Reforma). Vejamos o que diz o Plano de Gestão da RDS do Tupé (2016, p. 28):

Dessa forma será possível iniciar o processo de construção e formalização dos contratos de Concessão de Direito Real de Uso com as Comunidades tradicionais da área. Garantindo aos comunitários ter um documento para comprovar sua moradia e posse de terra, sendo esse passo fundamental para solicitar financiamentos, receber benefícios do Instituto Nacional do Seguro Social- INSS, fazer planos de Manejo dos recursos Naturais.

Ou seja, as famílias tradicionais que ocupam essas áreas, como os indígenas, agricultores, pescadores, artesãos e outros, não são consideradas donos das terras das quais residem, mesmo tendo chegado nessas terras há muitos anos e antes da criação legal das REDES do Tupé, devendo solicitar o CDRU para que obtenham o direito de posse e uso dessas terras sem que ocasionem prejuízos ao meio ambiente. A indicação é que toda a área da região deva ser matriculada na SEMMAS, a fim de que se adquira a concessão de posse e uso das famílias tradicionais que moram nessas áreas para que tenham permissão para exploração dos ecossistemas naturais em regime de manejo sustentável e a substituição da cobertura vegetal por espécies cultiváveis (Manaus, 2016, p. 29).

Em 2007, fizeram um levantamento nas áreas ocupadas pelas Comunidades com o apoio da Secretaria de Meio Ambiente (SEMMAS) e a Universidade Federal do Amazonas (UFAM), a fim de realizar o georreferenciamento das terras que compõem as REDES do Tupé. De acordo com o Plano de Gestão (2016, p. 28), o trabalho teve por objetivo ampliar o conhecimento ambiental e iniciar a estruturação participativa de banco de dados socioambientais da Unidade.

De acordo com o Plano de Gestão, foi realizada a Caminhada Ecológica com o auxílio dos moradores que conheciam bem as comunidades que formam a Reserva de Desenvolvimento Sustentável do Tupé. Essa caminhada ocorreu em trilhas abertas e em áreas sem trilhas a fim de identificar as espécies da fauna e flora presentes na UC. Após essa caminhada, foi identificada uma extensa diversidade animal e vegetal na reserva; algumas até então desconhecidas e, posteriormente, foram catalogadas todas as espécies com o objetivo de conservação das mesmas e do manejo consciente para que as famílias que residem nessas áreas tenham uma melhor qualidade de vida.

As famílias que moram na RDS (Reserva de Desenvolvimento Sustentável do Tupé) devem ter orientação de como utilizar seus recursos naturais e fazer seu uso de forma sustentável sem que ocasione a degradação da natureza e prejuízos futuros à comunidade. Para isso, é de fundamental importância conhecê-los para definir suas potencialidades, formas de uso e acesso aos recursos, bem práticas de manejo e destinação de áreas para conservação (Manaus, 2016 p. 46). O Plano de Gestão (2016, p. 46) também ressalta a grande biodiversidade presente na RSD do Tupé "[...] sustenta um valioso potencial de recursos florestais madeireiros, não madeireiros e de fauna que são utilizados pelas seis comunidades inseridas na unidade, bem como as de seu entorno (São Sebastião, Ebenezer, nossa Senhora de Fátima, Bela Vista, Araras, Tarumã-Açu, Baixote e Caioé)".

O livro projeto "BioTupé: meio físico, diversidade biológica e sociocultural do Baixo Rio Negro, Amazônia Central, organizado por Silva, et al (2005) realizado pelo Instituto Nacional de Pesquisas da Amazônia (INPA) em parceria com o Centro Universitário Luterano de Manaus (CEULM/ULBRA), no seu capítulo 10 (p. 141) sobre Diversidade Biológica, aponta que o homem possui relações de troca com o meio ambiente, ao passo que utiliza de seus recursos, também deve manter sua conservação. 
Ainda, de acordo, com esse estudo, o conhecimento sobre os recursos naturais e as formas de manejo implica em criar formas de preservá-los para as futuras gerações. Neste caso, as famílias tradicionais que vivem nessas áreas de reserva possuem uma importante participação na questão da conservação da biodiversidade e de manejo (utilização) dos recursos naturais de maneira sustentável. O trópico úmido é o bioma terrestre com maior diversidade biológica e onde se encontram as maiores extensões de terras não cultivadas, daí a preocupação de como usar e conservar o trópico úmido em geral e a maior dessas áreas, a Amazônia em particular (Moran, 1990 apud Manaus, 2016).

O Plano de Gestão das RSD do Tupé afirma que as áreas de reserva devem ser conservadas e que o uso de seus recursos naturais deve ocorrer apenas para suprir as necessidades de sobrevivência das populações tradicionais e de seus familiares, mas sem causar danos ao meio ambiente e as futuras gerações que também utilizarão desses recursos. Paralelo a isso, o Plano ressalta a importância dessas populações tradicionais de conhecerem a região e tudo o que a compõe, inclusive as formas corretas de como utilizar esses recursos (manejo) de forma sustentável.

Verificamos até aqui que o Plano de Gestão da RDS do Tupé relata uma elevada quantidade de riquezas naturais presentes nas unidades de conservação, tornando-se um dos centros de biodiversidade da Amazônia. O discurso de sustentabilidade aparece desde o início da sua criação, como podemos perceber, através das criações de leis e órgãos competentes com o objetivo de preservar o meio ambiente presente nas comunidades da reserva e de conservar seus recursos naturais.

No Plano de Gestão é contemplado o processo histórico de ocupação do Rio Negro e da história da Cidade de Manaus, com o objetivo de exemplificar melhor como se deu o processo de industrialização na região Amazônica, que através da implantação da Zona Franca de Manaus apresentou uma proposta de Desenvolvimento Sustentável que visava integrar a região ao restante do país e do mundo globalizado com vistas à expansão capitalista.

É relatado no Plano que no século XVII, quando iniciou o processo de Colonização, o Baixo Rio Negro era ocupado por uma extensa população indígena, dentre eles os povos Tarumã, Manaós e Barés. Nesta mesma época, houve um enorme extermínio dessas populações indígenas em decorrência de guerras travadas entre colonizadores e indígena, tanto quanto pela transmissão de muitas doenças provenientes do "homem branco", assim denominados pelos indígenas. Em decorrência dessas guerras e doenças, muitas das populações indígenas foram exterminadas; as que restaram, então passaram a se deslocar para outras regiões, como o Alto Rio Negro, ou mesmo permanecer na região, mas por consequência serem escravizados pelos colonizadores.

Mourão (2009, p. 22) relata que:

Os índios, que eram milhares e também considerados uma droga do sertão, frequentemente eram arrancados de seu habitat para trabalhar para o colonizador. Como resistiram de várias formas a exploração, foram sendo exterminados, a ponto de a Coroa começar a se preocupar com este fato, regulamentando o recrutamento da força de trabalho indígena, assim como as relações de trabalho vigentes no período.

De acordo com o Plano de Gestão (2016), entre o ano de 1950 e meados da década de 60, houve um novo processo de ocupação no Baixo Rio Negro por diversos grupos, dentre eles famílias que trabalhavam com extrativismo (produção da borracha), povos indígenas que vinham do Alto Rio Negro para Manaus e caboclos que haviam trabalhado em antigos seringais no médio e baixo Rio Negro [...]. O processo de industrialização que se desenvolvia na Europa necessitava de matérias-primas. No caso Amazônico, a borracha iria se constituir na principal mercadoria incorporada ao comércio internacional (Mourão, 2009, p. 25).

A borracha torna-se a principal mercadoria para o comércio internacional e, em consequência, a Amazônia iniciava sua atuação no capitalismo industrial, passando a ser considerada como região por conta desta mercadoria conforme Mourão 
(2009). Nesta fase de auge da borracha, surgiram políticas de Governo para a Amazônia em meados de 1965 com discurso de que fosse realizado um planejamento para que se desenvolvesse a região. Foi incentivado que se criasse pólos de desenvolvimento através de empresas privadas que seriam beneficiadas com a redução de impostos. Nesta compreensão, a Zona Franca de Manaus seria um pólo de desenvolvimento para a Amazônia Ocidental (Mourão, 2009 p. 35). Confirmamos no Plano de Gestão (2016) sobre a proposta de Desenvolvimento Sustentável na região que:

Em 1967 foi criado o Modelo Zona Franca de Manaus, por meio do Decreto-Lei 288, de 28 de fevereiro. Desde então, impulsiona a economia da região. Ao longo dessas quatro décadas, foi uma resposta ao desafio de formulação de uma política de desenvolvimento autossustentável, capaz de permitir a integração econômica da Amazônia, sem prejuízo ao seu patrimônio ambiental. O modelo ZFM foi o responsável por dinamizar a economia do estado do Amazonas e cujos efeitos positivos espraiaram-se para os demais Estados da área de atuação da autarquia. São mais de 500 indústrias aptas a produzir, utilizando tecnologia de ponta na produção, por exemplo, de eletroeletrônicos, bens de informática, aparelhos de telefonia celular, televisores e motocicletas. Tudo isso com qualidade certificada pelo Sistema Internacional ISSO na maioria das empresas. A dinâmica da ZFM compreende três polos econômicos: comercial, agropecuário e industrial (Manaus, 2016, p. 113).

Mourão (2009, p. 33) afirma que a Zona Franca de Manaus (ZFM) está inscrita no chamado "espaço global", articulada com a política de governo militar de integração e ocupação da Amazônia. A criação da ZFM foi uma medida de adequação da região ao capitalismo internacional, já que necessitava seguir o modelo de acumulação capitalista que estava se consolidando mundialmente; além de sua criação, outras medidas foram criadas no intuito de por em prática o plano de desenvolvimento para a Amazônia como construções e reforma de portos para facilitar o comércio, incentivo para que as empresas privadas se fixassem na região, disponibilização de verbas para o desenvolvimento econômico entre outros.

A autora (2009, p. 33) ainda caracteriza a última fase da criação da ZFM como sendo o período de crise. "A terceira fase tem início em 1991 e caracteriza-se como um período de crise, em virtude da política industrial e de comércio exterior do Governo Federal, que promoveu a abertura do mercado brasileiro às importações, possibilitando a entrada indiscriminada de produtos estrangeiros no país".

O Plano de Gestão (2016) enfatiza que as crises econômicas que ocorreram na década de 80 e 90 influenciaram na queda da ZFM com os cortes dos incentivos fiscais, com a queda da produção e, como consequência, com a onda de desempregos, além de tudo, ressalta que neste período houve um povoamento na região do Baixo Rio Negro, principalmente por moradores provenientes da cidade de Manaus que fugiam da crise. A partir da década de 80 , as famílias da região do baixo Rio Negro, estabelecidas inicialmente em sítios [...] passam a reivindicar alguns direitos e benefícios ao poder público (Manaus, 2016 p. 112).

Verificamos que a Proposta de Desenvolvimento Sustentável apresentada no Plano de Gestão das RDS do Tupé considera o desenvolvimento econômico como uma política de desenvolvimento sustentável para a região e que tem como objetivo integrar a região Amazônica à economia global e à acumulação capitalista, tornando-a atrativa ao mercado mundial.

Como citado acima, o termo Desenvolvimento regional Sustentável da Amazônia não pode estar associado apenas ao Desenvolvimento econômico que é referente à produção, distribuição e oferecimento de produtos ou serviços que visem lucro, mas também deve estar associado ao social, onde o bem estar individual e social, bem como interação dos indivíduos deve ser levado em consideração, oportunizando relações saudáveis e, ao ecológico, onde haja impacto ao meio ambiente de modo positivo, tanto quanto minimizando fatores negativos encontrados no ambiente causados por industrialização e similares; o que parece ser um grande desafio frente ao discurso de desenvolvimento da região que se baseia em globalizar a Amazônia através da acumulação do capital. 


\section{Metas e Estratégias do Plano de Gestão da RDS do Tupé}

De acordo com o Plano de Gestão (2016), a RSD do Tupé é uma Unidade de Conservação da Categoria de uso sustentável, isto significa que é permitida a permanência por populações tradicionais. Nessas comunidades existem famílias que efetivamente moram na reserva e outras que apenas passam os finais de semana, sendo que durante a semana residem na cidade de Manaus, onde seus filhos estudam, ou mesmo por conta de seus trabalhos na cidade. Há um grande fluxo desses moradores entre as comunidades e a cidade de Manaus.

Dentre esses moradores destacamos os indígenas, os ribeirinhos, os pescadores, os agricultores, os vendedores ambulantes que possuem barracas de venda de comida nas praias visitadas por turistas, entre outros. As comunidades que residem na área da Unidade, em sua maioria, vivem do manejo de recursos naturais como cultivos agrícolas, exploração madeireira, criação de pequenos animais e extrativismo animal com base na caça e na pesca (Manaus, 2016, p. 110).

De acordo com a Gestão da Unidade de Conservação do Tupé, podemos destacar as metas e estratégias apresentadas pelo Plano de Gestão, como Habitação, Infraestrutura, Educação, Saúde, Economia e Atividades Culturais.

Em relação à Habitação, as casas existentes nas comunidades da Reserva de Desenvolvimento Sustentável do Tupé são construídas de madeira, muitas vezes tirada da própria comunidade e outras são construídas de alvenaria, material comprado em comunidades vizinhas ou na própria cidade de Manaus; depois esse material é transportado de barco ou canoa para o local da obra. "[...] As construções seguem geralmente o padrão casas pequenas, [...] coberto na sua maioria com telhas de alumínio e tendo como material básico a madeira." (Nascimento, et al., 2007 apud Manaus, 2016).

De acordo com o Plano de Gestão (2016, p. 121), em relação às condições de saneamento, algumas residências não possuem sanitários e, quando possuem, esses ficam no quintal das casas, então, são conhecidos como "buraco negro". As casas das famílias, em grande parte, não possuem água encanada e sistema de esgoto; muitas das vezes para beber água ou tomar banho os moradores se deslocam diretamente para o rio ou igarapés mais próximos. A água utilizada para o consumo dos moradores vem de poços, da chuva ou dos igarapés (Nascimento, et al., 2007 apud Manaus, 2016).

A infraestrutura citada no Plano de Gestão das RDS do Tupé equivale a:

[...] escolas, energia elétrica, posto de saúde e o Centro de Apoio ao Desenvolvimento Sustentável Prof. Roberto Vieira, com banheiros públicos e alojamento para funcionários da SEMMAS, barracas de alimentação na praia do Tupé, além de Meios de Comunicação instalados por órgãos públicos, centros comunitários, poços artesianos, igrejas e comércios. Algumas comunidades possuem água encanada, como é o caso de Julião e Agrovila (Manaus, 2016, p. 121).

É ressaltado no Plano de Gestão que nem todas as Comunidades possuem esses serviços básicos, apenas nas sedes comunitárias. Neste caso, as outras comunidades devem dirigir-se a essas comunidades ou procurarem por esses serviços na cidade de Manaus. O plano ainda cita duas comunidades como exemplo; é o caso da Comunidade Colônia Central que não possui escolas, água encanada ou tratada e o posto de saúde foi construído pelos moradores, bem como a energia elétrica só atende a sede da Comunidade; e a Comunidade da Tatulândia onde não possui energia elétrica, escolas, posto de saúde e nem água encanada ou tratada.

Em relação à educação, destacou-se que a educação da cidade possui muitas falhas e que estas se tornam mais evidentes nas zonas rurais, e principalmente, nas comunidades localizadas nas reservas, onde aqui podemos citar carência de professores, dificuldade de acesso das crianças à escola, inadequação do ano letivo à sazonalidade e às atividades agrícolas regionais; no uso dos materiais didáticos e no desenvolvimento de programas de ensino em contradição com a realidade local. Essas dificuldades acentuam-se na realidade a RDS do Tupé, pois as distâncias geográficas somam-se as ações ainda mais limitadas do poder público. 
Em relação ao ensino, segundo o Plano de Gestão (2016), parte considerada da população da comunidade não possui o ensino médio. Então, a grande maioria decide ou não prosseguir em seus estudos e seguir somente trabalhando nas comunidades ou irem para a cidade de Manaus concluírem seus estudos e de seus filhos. A Secretaria Municipal de Educação (SEMED) instituiu em 2008 o ensino do $6^{\circ}$ ao $9^{\circ}$ ano, através do projeto "Itinerante" onde o ensino é realizado por módulos concentrados de disciplinas em período de três meses, em oito comunidades da região. Foi realizado em 2013, em parceria com a Secretaria de Estado de Educação e Qualidade do Ensino (SEDUC), o ensino à distância do $1^{\circ}$ ao $3^{\circ}$ ano do segundo grau.

Sobre o ensino e aprendizagem dos estudantes das comunidades da reserva, destaca-se, conforme o Plano de Gestão (2016, p. 123):

As crianças da REDES DO Tupé dispõem de poucos materiais escolares para o desenvolvimento das atividades de aprendizagem, ficando tão somente com o básico: caderno, canetas lápis e borracha. Nem todas as bibliotecas das escolas dispõem de material literário infantil, que seriam um dos responsáveis pelo despertar do imaginário das crianças.

Além das dificuldades apresentadas acima, é ressaltada outras situações que comprometem o ensino das crianças das RDS do Tupé, como é o caso da falta de apoio dos pais junto a seus filhos nas práticas escolares, por não terem instrução e possuírem pouca escolaridade. Fato que ocasiona que as crianças não tenham um desenvolvimento escolar condizente com uma criança que recebe o apoio de seus pais.

Outro fator bem relevante, que está na lista das dificuldades apresentadas nas comunidades da reserva quanto à educação, são as longas distâncias enfrentadas tanto pelos estudantes quanto por professores (as) e funcionários (as) da escola. Sendo que muitos dos professores que residem na cidade de Manaus, tem de se deslocar para a escola por meio de transporte fluvial, no caso uma lancha, oferecido pela secretaria de educação, de modo que quando ocorre algum problema com a lancha, ou falta gasolina para seu funcionamento, não tem como haver aula, o que prejudica o desenvolvimento das crianças na escola.

O Plano de Gestão ressalta que as escolas possuem um calendário especial que condiz com a realidade dos períodos de seca e de cheia dos rios e que nos casos de seca, as crianças são as que mais sofrem por terem de percorrer longas distâncias para chegarem às escolas que estão matriculadas. Em alguns casos, certas crianças caminham cerca de $5 \mathrm{~km}$ de suas residências até à escola, situada na área central da comunidade (Nascimento, 2007 apud Manaus, 2016, p. 124).

Sobre o órgão responsável pelas políticas públicas educacionais nessas comunidades, o Plano de Gestão (2016, p. 124) afirma que:

A Prefeitura de Manaus, através da Secretaria Municipal de Educação - SEMED é o órgão responsável pela política educacional desenvolvida na reserva. Existem na área quatro escolas de Ensino Fundamental, nas Comunidades de Agrovila (Escola Municipal Paulo Freire), no Livramento (Escola Municipal São José I), no Julião (Escola Municipal II), São João do Tupé (Escola Municipal São João). Os alunos das comunidades Colônia Central e Tatu estudam nas escolas da Comunidade São João e Julião. As escolas Paulo Freire e São José I já possuem o Ensino Médio Presencial com mediação tecnológica.

O Plano ainda menciona os deveres da Prefeitura de Manaus como responsável pela educação nas áreas de reserva, por serem consideradas zonas rurais de Manaus, dentre os deveres destaca-se a construção de escolas, pagamentos dos salários dos professores, condutores fluviais, merendeiras e vigias, transporte para os professores e alunos, material didático, merenda escolar, combustível para o funcionamento do gerador de energia e pagamento de conta de energia elétrica (Manaus, 2016).

Essas comunidades são assistidas por postos de saúde, totalizando um número de seis postos na região, fundados pelo Sistema Único de Saúde (SUS) ou pela Fundação Nacional de Saúde (FUNASA). De acordo com o Plano de Gestão (2016), 
esses postos são administrados por enfermeiros e possuem muitas dificuldades de funcionamento por sua falta de estrutura física, falta de materiais e de pessoal, como técnicos e agentes de saúde para visita a população.

Em relação a doenças que atingem os moradores da reserva, é citado que as mais frequentes nos últimos anos nas comunidades da REDES do Tupé são a malária, ocorrendo com intensidade em períodos específicos, como a vazante; viroses, pneumonia e rotavírus (Nascimento, et al., 2007 apud Manaus, 2016).

Os moradores utilizam água da chuva, poços e igarapés para beber, tomar banho ou preparar alimentos. Ainda, é possível afirmar que nem todos os moradores, ou a sua grande maioria, não consome uma água de boa qualidade. No plano, cita-se que nas comunidades de Julião e Agrovila, foram construídos poços artesianos, com recursos do consulado do Japão, para levar água encanada para os comunitários (Manaus, 2016).

Em relação ao Turismo da região, a REDES do Tupé está dentro da área da abrangência do Plano de Desenvolvimento Sustentável do Ecoturismo coordenado pelo Programa de Desenvolvimento Sustentável do Ecoturismo na Amazônia Legal - PROECOTUR que inclui 14 municípios, dentre eles Manaus (Manaus, 2008 apud Manaus, 2016).

De acordo com este Plano de Desenvolvimento Sustentável do Ecoturismo, a praia do Tupé é considerada um dos atrativos turísticos da cidade de Manaus. Ela é destino de muitos turistas que visitam a região em busca de lazer e diversão. Nela podem ser encontradas barracas de vendas de comidas e bebidas, além de uma praia, que na época de seca transformamse em grandes dunas de areia.

É possível encontrar na região trilhas que levam a cachoeiras, flutuantes que oferecem equipamento e pessoal especializado para que o turista alimente os botos diretamente no rio, além de visitas a comunidades indígenas, a fim de assistirem a apresentações culturais e compra de artesanato elaborado por eles mesmos. Dentre as opções de lazer podemos citar as visitas às praias, almoço nas barracas na praia do Tupé, acampamentos, assistir rituais indígenas na Comunidade São João, visitar o seringal na Vila Paraíso, onde foi gravado o filme “A Selva” (Manaus, 2008 apud Manaus, 2016, p. 137).

Vejamos o que diz o Plano de Gestão (2016, p. 136) sobre o Turismo na região da Reserva de Desenvolvimento Sustentável do Tupé:

O ponto de maior concentração de visitantes na REDES do Tupé é a praia do Tupé, além de outras praias populares nos fins de semana como Escondidinho, Amor, Luciano e Arrombado. Muito movimento de turistas estrangeiros nas malocas indígenas da Comunidade São João. Outras áreas de recreação são as trilhas, praias, cachoeiras, pousadas e hotéis.

A Prefeitura de Manaus em parceria com a SEMMAS e a Escola Municipal de Serviço Público disponibilizaram para 100 comunitários um Programa de Qualificação do Segmento Turístico que emitiu certificação para todos os que participaram. Este programa foi elaborado pela Escola Municipal de Serviço Público (ESPI), Secretaria de Meio Ambiente e Sustentabilidade (SEMMAS) e Fundação Municipal de Cultura, Turismo e Eventos (Manaus Cult). Por meio de aulas práticas e teóricas, os alunos aprenderam sobre a manipulação de alimentos e bebidas, formatação de roteiro turístico aprendendo a empreender, elaboração e apresentação de cardápios e, por último, monitoramento ambiental. (Manaus, 2016, p. 137)

Dentre as maneiras de lazer citadas, podemos destacar as partidas de futebol realizadas nas comunidades por homens, mulheres e crianças todos os dias no final da tarde, além de torneios e campeonatos que envolvem várias comunidades da região. As diversas formas de lazer são realizadas por todos como componentes para o fortalecimento dos laços de amizade e da identidade sociocultural das comunidades (Manaus, 2016, p. 138).

Os moradores utilizam de sua criatividade para elaborar atividades de distração para eles e para os visitantes que desejam visitar as comunidades. Podemos citar os festejos que acontecem nas comunidades Católicas da reserva, após as celebrações dedicadas ao padroeiro daquela comunidade. No dia que é realizado os festejos, acontecem grandes 
movimentações em todas as comunidades que se reúnem para socializar, dançar, cantar, comer, derrubar o mastro (tradição comum que ocorre há anos pelos moradores); ou seja, um dia de muita alegria para a comunidade anfitriã.

Sobre o artesanato, podemos destacar que a produção artesanal na Comunidade São João é realizada pelos indígenas e comunitários que fabricam colares, pulseiras, brincos, prendedores de cabelos, lautas, conchas, adornos, peneiras, pratos, potes, e torradeiras. O material utilizado na fabricação desses artesanatos são as fibras de tucum e arumã, cipós, sementes e argilas. $\mathrm{Na}$ comunidade do Julião, parte da população trabalha com cestaria, tipiti e esteiras ou tapetes feito de arumã, geralmente de formato quadrado ou retangular, variando muito de tamanho (Manaus, 2016, p. 140).

Na comunidade de São João do Tupé, onde se encontra a etnia Dessana, pode-se ver em maior quantidade e variedade os artesanatos que são confeccionados pelas famílias indígenas e oferecidos aos turistas após as apresentações realizadas como atrativo turístico. Pode-se perceber a riqueza de detalhes nas belas peças feita a mão com matérias-primas oriundas da natureza. Nessa Comunidade, temos a oportunidade de conhecer e desfrutar da cultura desses povos tradicionais, que ainda estão sobrevivendo na região, através do artesanato, dança e música, comidas e bebidas típicas. Do ponto de vista da preservação das tradições culturais, a produção artesanal também funciona como forma de transmitir e valorizar o conhecimento da confecção e uso das peças para gerações futuras (Manaus, 2008 apud Manaus, 2008, p. 139).

Na Comunidade de São João tinha a presença do Pajé do povo Dessana, senhor Raimundo Vaz, que morreu no ano de 2018 e era conhecido nacional e internacionalmente por conhecer muitas propriedades medicinais das plantas da região. Muitos moradores dirigiam-se até ele para que indicasse quais chás deveriam tomar para ficarem curados de algum mal que lhes acometessem. Os moradores da comunidade e das adjacências recorriam a ele por falta de atendimento médico na região, sendo ele, muitas vezes, a única opção.

Sobre a presença de uma Associação indígena na região da reserva do Tupé, o plano retrata:

Há também uma Associação Indígena na Comunidade do Livramento, composta por identidades Baré, Mura,Tikuna, Apurinã e XiKrin. Com o intuito de resgatar a identidade, eles construíram uma maloca na beira do Rio Negro, que apresenta formato quadrangular e não possue paredes, onde fazem danças e comidas típicas (Manaus, 2008 apud Manaus, 2016, p. 136).

A presença indígena é mais intensa na Comunidade de São João do Tupé, com a presença da etnia Dessana que vive das apresentações culturais, onde é cobrada uma taxa aos turistas que desejem visitar e conhecer um pouco mais da sua cultura através de danças, músicas, degustação de comidas típicas, venda de artesanato e pinturas realizadas por jovens indígenas.

$\mathrm{Na}$ oportunidade de conhecer a etnia Dessana, o turista ainda tem a oportunidade de visitar os demais locais no seu interior, como o local que é preparado o alimento, a maloca de apresentações, as malocas onde viviam com suas famílias e etc. Nesses locais onde ocorrem as apresentações, os indígenas não moram com suas famílias, pois passaram a morar em casas na vila da Comunidade São João do Tupé próximo a praia. Essas apresentações culturais funcionam todos os dias no horário comercial e é uma forma de sobrevivência e de sustento para o indígena e a sua família. Os indígenas também participam das atividades presentes na comunidade como catequese, celebrações, festejos, escola, campeonatos, associação, entre outros.

\section{Considerações Finais}

Dentre todas as informações apresentadas pelo Plano de Gestão da RDS do Tupé, percebemos que existem muitas contradições em relação ao meio amazônico e a região das reservas. De acordo com o IBGE (2014-2015), a população do município de Manaus equivale a 2.057.711 habitantes, sendo a população urbana de 1.792 .881 .724 e a população rural de 9.133 habitantes. Esses dados revelam o grande fluxo de pessoas situadas na cidade de Manaus, enquanto que no interior do Estado, que é composto por 62 municípios, ainda se tem um número bem inferior quando comparado com a capital do Estado, 
revelando a preferência das populações, até daquelas do interior do Estado em migrarem para a capital em busca de melhores condições de vida e de trabalho, visto que na zona rural de Manaus e até em outros municípios, é grande a falta de políticas públicas que atendam essas populações em todas as suas necessidades, tal como infraestrutura, educação, saúde, lazer e etc.

Na RDS do Tupé, o cenário não é diferente da realidade mencionada acima, pois constatamos alguns pontos contraditórios no Plano de Gestão da RDS do Tupé em relação a questões de infraestrutura, educação, saúde, lazer e outros. Inicialmente destacamos quanto à questão da infraestrutura, onde ainda faltam políticas públicas que atuem nessas áreas e que se concretizem em ações que beneficiarão as comunidades que formam a REDES do Tupé.

No Plano de Gestão (2016, p. 121) é ressaltado que a infraestrutura básica existente nas Comunidades é escolas, energia elétrica, posto de saúde e o Centro de Apoio ao Desenvolvimento Sustentável, de nome Prof. Roberto Vieira, com banheiros públicos e alojamentos para funcionários da SEMMAS, barracas de alimentação na praia do Tupé, além de Meios de Comunicação instalados por órgãos públicos, centros comunitários, poços artesianos, igrejas e comércios. Porém, não são em todas as comunidades que se encontra a infraestrutura citada e, para além, em outras comunidades existe parte; muitas das obras foram construídas pelos próprios moradores sem intervenção do poder público.

Podemos citar na Comunidade de São João do Tupé, onde os moradores tentam construir a igreja São João há mais de dez anos; que ao invés de posto de saúde, existe uma casinha de saúde que está sem profissionais da área atendendo no local; onde a estrutura da Associação de moradores está precisando de reformas e a escola precisa atender os estudantes que desejam terminar o ensino médio sem ir para a cidade para conclusão de seus estudos.

$\mathrm{Na}$ questão de educação, nem todas as comunidades possuem escolas, apenas quatro delas, sendo Agrovila, Livramento, Julião e São João do Tupé. Os moradores das outras comunidades devem se deslocar de sua comunidade para estudar em uma dessas escolas ou irem para a cidade de Manaus. O Plano de Gestão apresenta algumas dificuldades enfrentadas pelos estudantes da região ao tentar ingressar na escola e na sua permanência ao concluir seus estudos, porém na realidade essas dificuldades se intensificam e se tornam grandes desafios na educação dos estudantes da RDS. A falta de mais escolas, de um planejamento pedagógico adaptado de acordo com a vida e trabalho, de materiais didáticos condizentes com a sua realidade, da abertura do ensino até o segundo grau, de meios de transporte que facilitem o acesso à escola nas épocas de cheia e entre outras necessidades, precisam ser viabilizadas por meio de políticas públicas educacionais para que facilitem a educação escolar na reserva e impeçam a evasão escolar de seus alunos.

Em relação à saúde, verificamos que os postos citados no Plano de Gestão não atendem todas as comunidades com uma assistência médica de qualidade, fazendo com que a população recorra à cidade de Manaus ou procure alternativa na própria comunidade.

\section{Agradecimentos}

À Coordenação de Aperfeiçoamento de Pessoal em Nível Superior - CAPES e Fundação de Amparo à Pesquisa do Estado do Amazonas - FAPEAM pelo financiamento da pesquisa.

\section{Referências}

Brasil (2000). Lei n ${ }^{\circ}$ 9.985, de 18 de Julho de 2000. Regulamenta o art. 225, § 1o, incisos I, II, III e VII da Constituição Federal, institui o Sistema Nacional de Unidades de Conservação da Natureza e dá outras providências. http://www.planalto.gov.br/ccivil_03/leis/19985.htm

Brasil. (1988). Constituição da República Federativa do Brasil de 1988. Promulgada em 5 de outubro de 1988. http://www.planalto.gov.br/ccivil_03/c onstituicao/constituição.htm.

Brizolla, M. M. B., Allebrandt, S. L., Silva, P. R. da, Hedlund, P. R., \& Zanatta, J. M. (2020). Políticas ambientais: uma avaliação dos desafios e das perspectivas do município de Ijuí/RS. Research, Society and Development, 9(4), e89942797. https://doi.org/10.33448/rsd-v9i4.279 
Research, Society and Development, v. 10, n. 8, e45110817506, 2021

(CC BY 4.0) | ISSN 2525-3409 | DOI: http://dx.doi.org/10.33448/rsd-v10i8.17506

Bruseke, F. J (1995). O problema do Desenvolvimento Sustentável. In: Cavalcanti, C (org.). Desenvolvimento e Natureza: Estudos para uma sociedade Sustentável. Cortez.

Enríquez, M. A (2010). Trajetórias do Desenvolvimento: da ilusão do crescimento ao imperativo da sustentabilidade.

Ferreira, R. de S. (2020). A importância do direito ambiental para o desenvolvimento sustentável e a preservação do meio ambiente. Research, Society and Development, 9 (7), e194972591. https://doi.org/10.33448/rsd-v9i7.259

GIL, A. C (2002). Como elaborar projetos de pesquisa. Atlas.

Gonzaga, A. M (2007). Abordagens sobre a Pesquisa Científica. Amarildo Menezes Gonzaga (Org.). CEFET-AM. BK Editora.

Manaus (2008). Secretaria Municipal de Meio Ambiente. Plano de Manejo da Reserva de Desenvolvimento Sustentável do Tupé.

Manaus (2015). Secretaria Municipal de Educação. Lei no 2.000/2015. Plano municipal de educação do município de Manaus.

Manaus (2016). Secretaria Municipal de Meio Ambiente. Plano de Gestão da Reserva de Desenvolvimento Sustentável do Tupé Amazonas - Volume I. Revisão Final.

Manaus. Decreto n . 8044, de 25 de agosto de 2005. Cria a Reserva de Desenvolvimento Sustentável do Tupé. Diário Oficial de Manaus.

Mourão, A. R (2009). A industrialização do Estado do Amazonas. In: Baçal, S (org.). Trabalho, Educação, Empregabilidade e Gênero. Manaus: EDUA.

Noda, S, N (2007). Agricultura Familiar na Amazônia das Águas. Manaus: EDUA.

Pereira, A. S. et al (2018). Metodologia da pesquisa científica. UFSM.

Silva, E. N e t al (2005). BioTupé: meio físico, diversidade biológica e sociocultural. Biologia Geral e Experimental.

Silva, L. R C da (2009). Pesquisa documental: alternativa investigativa na formação docente. In: IX Congresso Nacional de Educação -EDUCERE. Https://educere.bruc.com.br/arquivo/pdf2009/3124_1712.pdf

Simonian, L. T. L (2005). Políticas Públicas, Desenvolvimento Sustentável e Recursos Naturais em Áreas de Reserva na Amazônia Brasileira. In: Coelho, M. C. N; MATHIS, A. Políticas Públicas e Desenvolvimento Local na Amazônia: uma agenda de debate. UFPA. 